\title{
Specific morphological characteristics of the coronary arteries
}

Discipline of anatomy, Department I - preclinical disciplines, Faculty of medicine, University "Ovidius" Constanţa

\begin{abstract}
In $68 \%$ of cases, the left coronary ostium is at the free edge of the left sigmoid valve in $22 \%$ of cases over the edge of the valve and in $8 \%$ of cases under the free edge of the valve. In $56 \%$ of cases, the right coronary ostium is at the free edge of the left sigmoid valve in $28 \%$ of cases over the edge of the valve and in $16 \%$ of cases under the free edge of the valve. We found 5 cases with two right coronary ostium and 2 cases with two left coronary ostium. We found that in $38 \%$ of cases, the left coronary artery ends in three branches, such as anterior interventricular, circumflex and left marginal arteries, in rest of the cases, the left coronary artery ending by two branches like the anterior interventricular and circumflex arteries in which case the marginal artery originate from circumflex artery and rarely from anterior interventricular artery, or both, in this last case the left marginal artery being double. We found only 8 cases in which the circumflex artery ends as posterior interventricular artery in rest of the cases being represented by the right coronary artery end. Circumflex artery ends by two branches quite often and rarely with three branches which can sometimes be long, down to near the apex of the heart. In $8 \%$ of cases, the circumflex artery was less developed and do not vascularize other than the left side of the posterior surface of the left ventricle, sometimes his terminal ramus being left marginal artery. The right coronary artery frequently ends on diaphragmatic surface of the heart either as a single branch in posterior interventricular groove, by bifurcation or even rarely by trifurcation, when one or two branches are located in the posterior interventricular groove. Sometimes the right coronary artery ends on the posterior surface of the
\end{abstract}

\section{Iliescu D.M.}

Department of Anatomy, Faculty of medicine, University "Ovidius" Constanţa, Romania

Aleea Universitatii, Nr. 1, Campus B, Constanţa, Romania dan@anatomie.ro left ventricle, where the posterior interventricular artery occurs as collateral branch of the right coronary artery, the right coronary artery extending their vascularization territory to the posterior surface of the left ventricle, right up to the apex of the heart, the right coronary dominance, the circumflex artery in this case ending on the lateral surface of the heart. The right coronary artery may end up on the posterior surface of the right ventricle in which case posterior interventricular artery is represented by the terminal portion of the circumflex artery. The right coronary artery rarely ended as the posterior interventricular artery can reach the apex of the heart. We have found that the dominant type of a coronary artery can be held not only in the number of collateral, but also by their caliber at their origin from the aorta. We encountered 7 cases in which there is a third coronary artery, in 5 cases the third coronary artery being an anterior right ventricular branch and I called her middle coronary artery or right anterior ventricular artery, and in two cases the third coronary artery represent the circumflex artery. In 6 cases of the 7 cases described the third coronary artery showed no atrial branches.
Keywords:
coronary
artery-morphological

characteristics

\section{Introduction}

Coronary arteries or heart arteries (cardiac arteries) are two in number, one anterior or left and another right or posterior. The coronary artery name comes from the fact that together they form a kind of crown around the heart. They arise from the initial portion of the aorta at the sinus of Valsalva, left coronary artery giving birth generally located at a level higher than the right and its size is often larger 
than the right coronary. Their origin is located at the level of the right and left anterolateral sigmoid valve, but this origin is located in a manner that the free edge of the sigmoid valves in ventricular systole is applied to the aortic wall below the coronary orifices, their disposal not influence coronary circulation $[1,2]$. Underlying visceral pericardium, the coronary arteries occupy heart grooves and are accompanied by coronary veins, lymphatic and nerve plexus trunks, the vessels being surrounded by the fat. Rarely straight, coronary arteries and their branches presents on the surface of the heart a tortuous course this fact would explain the changes in shape and volume that presents heart during systole, and this is a vessels functional adaptation to the revolution cardiac, each convolution corresponding to a reservation of elongation $[3,4]$.

\section{Materials and methods}

Our study was performed by dissecting the formalin preserved hearts, on fresh hearts practicing injection of contrast substance followed by radiography and plastic mass injection (Technovit 7143 ), followed by corrosion with $\mathrm{NaOH}$. We also examined the coronary arteries on angioCT made by Diagnostic Center Pozimed being executed on a computer tomograph GE LightSpeed VCT64 Slice CT.

\section{Results}

In $68 \%$ of cases, the left coronary ostium is at the free edge of the left sigmoid valve in $22 \%$ of cases over the edge of the valve and in $8 \%$ of cases under the free edge of the valve. In $54 \%$ of cases left ostium is in the middle portion of the the sigmoid valve in $28 \%$ of cases closer to the front end of the valve and
$18 \%$ of cases in the posterior half of the valve the sigmoid.

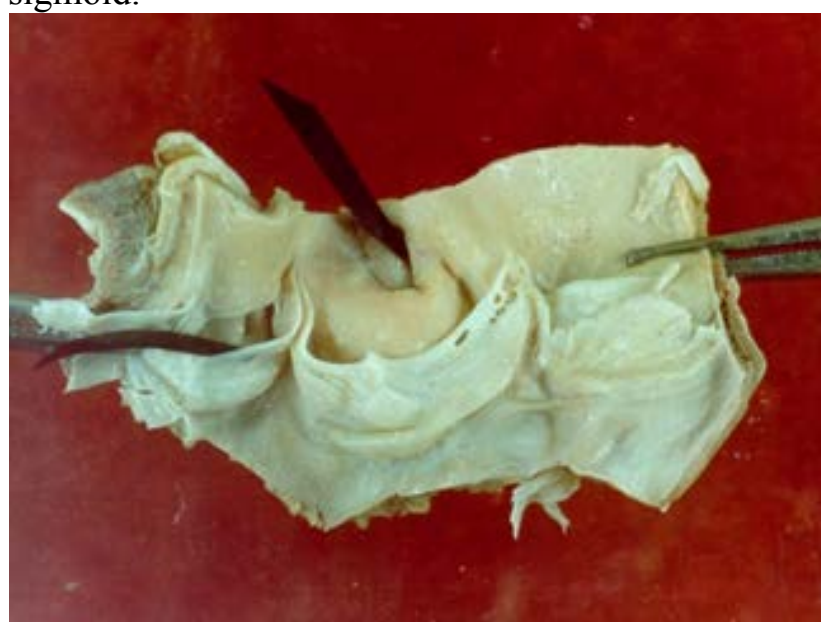

Figure 1 - Ostiums of the coronary arteries; right ostium above the free margin of the cusp and left ostium in a lower position, under the margin of the cusp.

In $56 \%$ of cases, the right coronary ostium is at the free edge of the left sigmoid valve in $28 \%$ of cases over the edge of the valve and in $16 \%$ of cases under the free edge of the valve. In $26 \%$ of cases right ostium was located at the middle of the valve, in $58 \%$ at the posterior and $16 \%$ at the anterior of the valve.



Figure 2 - Trifurcated left coronary artery

We found 5 cases with two right coronary ostiums and 2 cases with two left coronary ostiums.

Some authors [2] found that coronary artery ostium place over medium portion of the sigmoid valve and $[3,4,5,6,7]$ found it above the corresponding semilunar valves. Also, [8] found that $15 \%$ of the left 
coronary ostium is located at the free edge of the valve the sigmoid.

We found that in $38 \%$ of cases, the left coronary artery ends in three branches, such as anterior interventricular, circumflex and left marginal arteries, in rest of the cases, the left coronary artery ending by two branches like the anterior interventricular and circumflex arteries in which case the marginal artery originate from circumflex artery and rarely from anterior interventricular artery, or both, in this last case the left marginal artery being double.

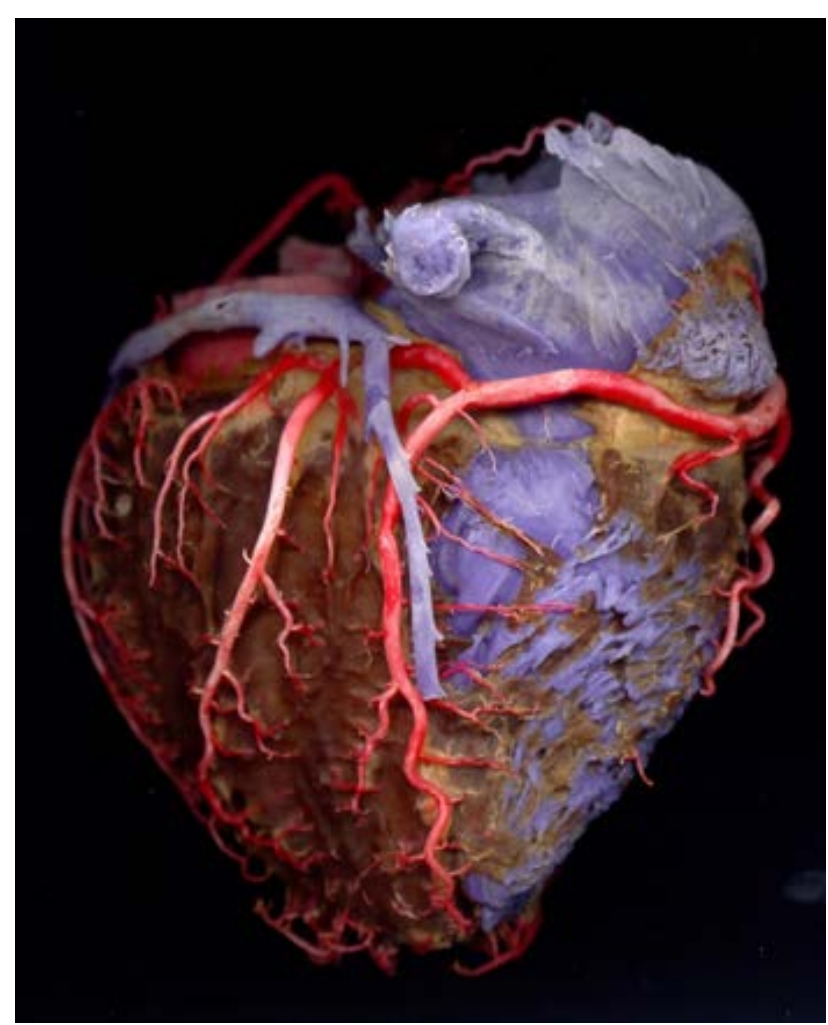

Figure 3 - Right coronary artery that ends on the posterior face of the left ventricle

We found only 8 cases in which the circumflex artery ends as posterior interventricular artery in rest of the cases being represented by the right coronary artery end. [6] refers to the possibility of the circumflex artery to be able to end as a posterior interventricular artery, and [8] find the variant in 10\% of cases. Circumflex artery ends by two branches quite often and rarely with three branches which can sometimes be long, coming down on the posterior surface of the left ventricle almost to the apex of the heart. When is unique, has a caliber greater than the anterior interventricular artery, [7] found him 4 $\mathrm{mm}$. In $8 \%$ of cases, the circumflex artery was less developed and do not vascularize than the left side of posterior surface of the left ventricle, its terminal rami sometimes being left marginal artery, appearance encountered by [8] in $20 \%$ of cases.

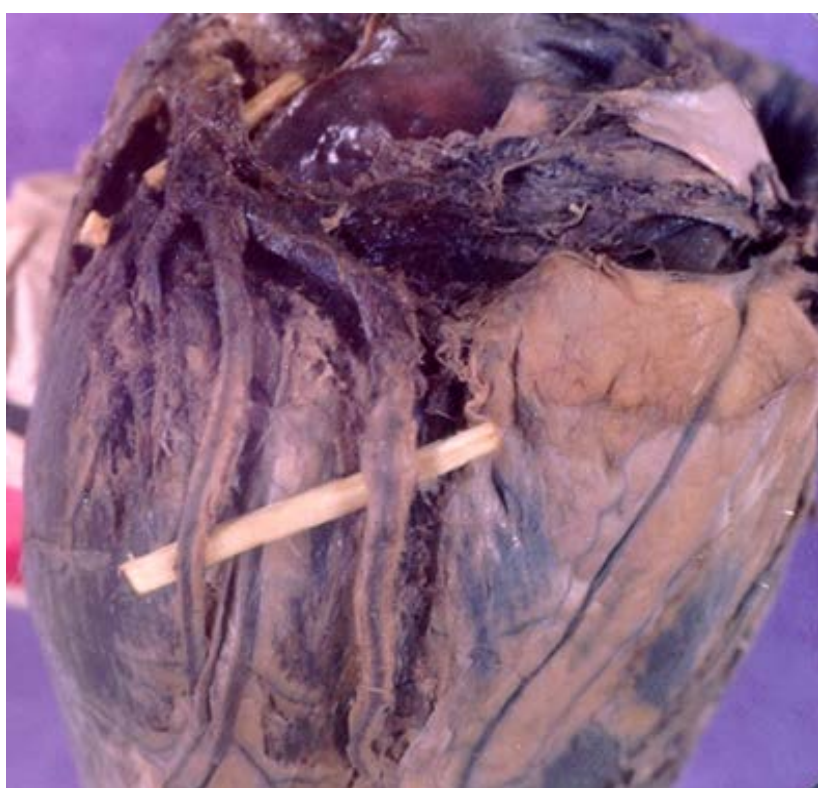

Figure 4 - Posterior interventricular artery represented by the termination of the circumflex artery

The the right coronary artery frequently ends on the diaphragmatic surface of the heart either as a single branch in posterior interventricular groove ,by bifurcation or even rarely by trifurcation, when one or two branches are located in the in posterior interventricular groove. Posterior interventricular artery usually does not reach the apex of heart terminating at a distance of $2.5 \mathrm{~cm}$ [7] or 1-3 cm [2], on the inferior part of the groove finding the anterior interventricular artery. 


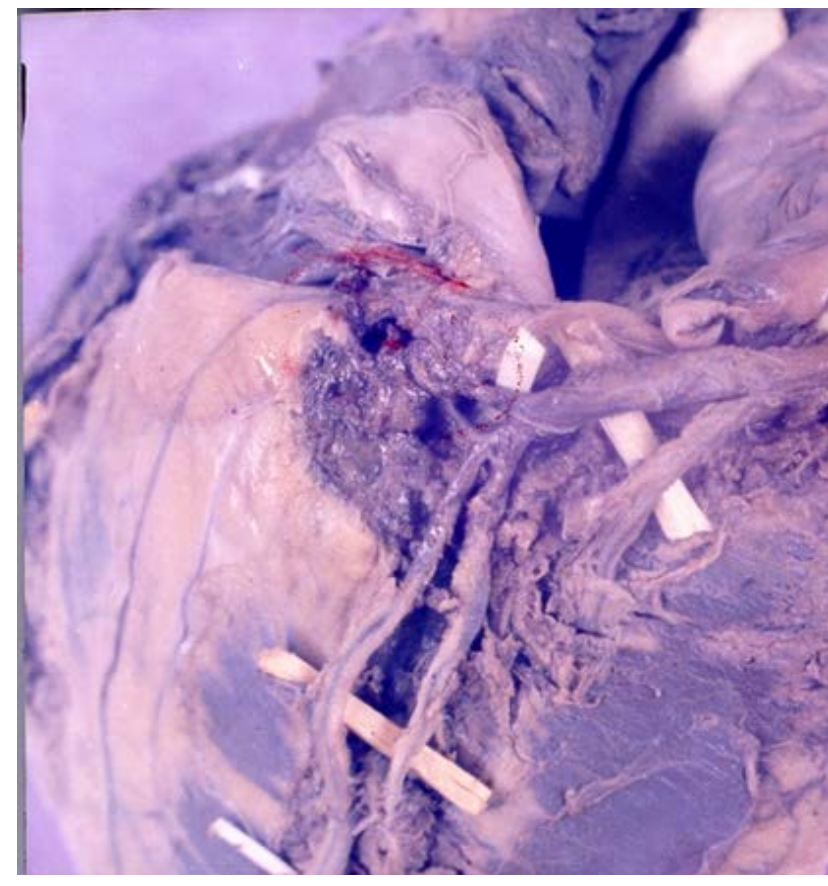

Figure 5 - Right coronary artery ending by two posterior interventricular arteries

Sometimes the right coronary artery ends on the posterior surface of the left ventricle, where the posterior interventricular artery occurs as a collateral branch of the right coronary artery, the right coronary extending their vascularization territory at the level of posterior surface of the left ventricle, right up to the apex of the heart, the right coronary dominance, the circumflex artery in this case ending on the lateral surface side of the heart.

The right coronary artery may end up on the posterior surface of the right ventricle, in which case posterior interventricular artery is represented by the terminal portion of the circumflex artery.

We encountered 7 cases in which there is a third coronary artery, in 5 cases the third coronary artery being an anterior right ventricular branch and I called her middle coronary artery or right anterior ventricular artery, and in two cases the third coronary artery represent the circumflex artery. In 6 cases of the 7 described cases, the third coronary artery showed no atrial branches.

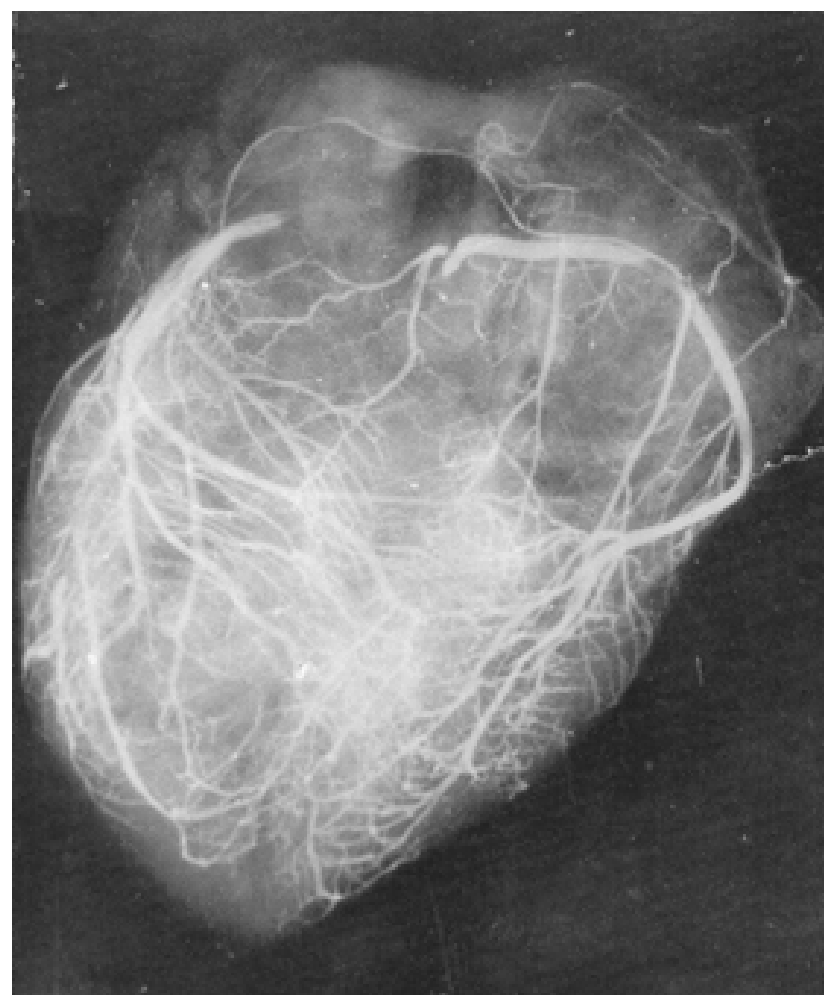

Figure 6 - Two right coronary arteries, the supplementary being an anterior ventricular artery

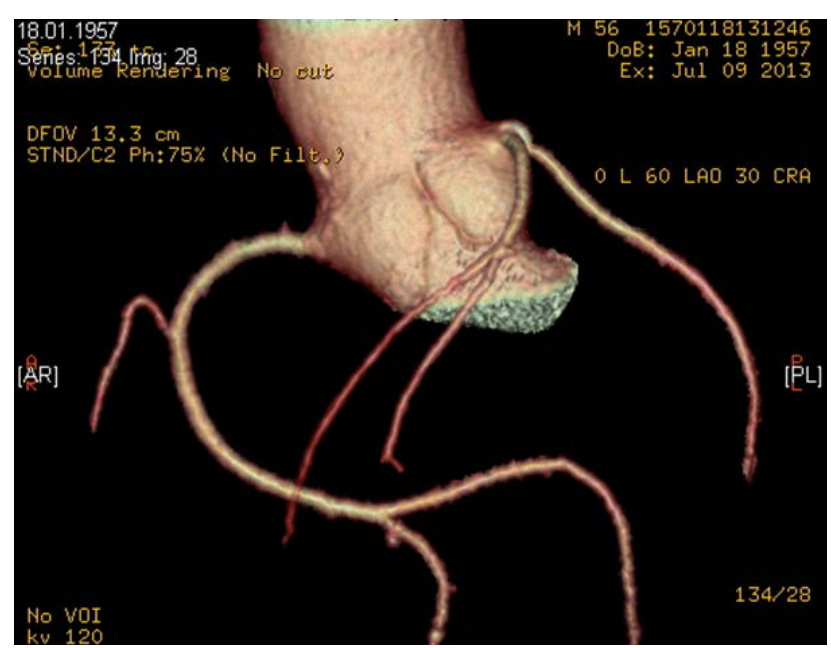

Figure 7 - Circumflex artery with aortic origin. 


\section{Conclusions}

Variants of origin, trajectory and branching of the coronary arteries and their branches are multiple. In surgical practice it is important to know especially those variants that interest the main branches to avoid the risk of confusion the surgeon during the intervention (6). Important in the morphology of the coronary arteries is their size and its branches, especially for anterior interventricular, at the level of which is most frequently performed the coronary bypass surgery. That is why are comparative studies of its caliber with radial and internal thoracic artery caliber, preferring the radial artery bypass because there are cases where greater saphenous vein is not useable (eg varicose veins) or when you need anterior interventricular artery bypass and the size of the internal thoracic artery is insufficient [9].

\section{References}

1. Paturet G. (1958). Traité d'anatomie humaine. Tome.III, (pp. 242). Paris: Ed. Masson

2. Rouvière H. \& Delmas A. (1997). Anatomie humaine descriptive, topographique et fonctionn elle. Tome 2. Tronc. (pp. 152-156). Paris: Ed. Masson

3. Testut L. (1921). Traité d'anatomie humaine. Angéiologie, livre IV, (pp. 118-122). Paris: Ed.Gaston Doin

4. Testut L. (1924). Traité d'anatomie humaine. Angéiologie. (pp. 509-511). Paris: Ed.Gaston

5. Kamina P. (1997). Anatomie. Introduction à la clinique. Dos et torax. (pp. 209-212). Paris: Ed Maloine

6. Christide C. \& Cabrol C. (1996). Anatomie $d u$ coeur et du pericarde. In: J.P.Chevrel. Anatomie clinique. Le tronc. (pp. 161-172). Paris: Ed Springer-Verlag

7. Bouchet A. \& Cuilleret J. (1991). Anatomie topographique, descriptive et fonctionnelle. Tome 2. Le cou. Le thorax. (pp. 1010-1019). Paris: Ed. Simep

8. Standring S. (2005). In: Gray's Anatomy. (pp. 1014-1018). Ed. Elsevier-Churchill Livingstone

9. Barry M., Foulon P., Touati G., Sevestre H. \& Laude M. (2003). Biométrie et structure des artères coronaires, thoracique internes gauche et radiales. Morphologie, 87, 13-15 